\title{
Proinflammatory cytokines in irritable bowel syndrome: a comparison with inflammatory bowel disease
}

\author{
Antigony Mitselou ${ }^{1}$, Vasileios Grammeniatis ${ }^{2}$, Anna Varouktsi ${ }^{3}$, Stamatis S Papadatos ${ }^{4}$, Konstantinos Katsanos $^{5}$, \\ Vasiliki Galani $^{6}$ \\ ${ }^{1}$ Department of Forensic Pathology, Medical School University of Ioannina, Ioannina, ${ }^{2}$ Department of Paediatrics, General Hospital of \\ Ioannina, Ioannina; ${ }^{3}$ Department of Internal Medicine, Ippokratio Hospital, Thessaloniki; ${ }^{4} 3 r d$ Department of Internal Medicine, Sotiria \\ General Hospital, National and Kapodistrian University of Athens Medical School, Athens; ${ }^{5}$ Hepato-Gastroenterology Unit, 1st Department of \\ Internal Medicine, and ${ }^{6}$ Department of Anatomy, Histology, and Embryology, Medical School University of Ioannina, Ioannina, Greece
}

Background/Aims: Irritable bowel syndrome (IBS) is a common disease often considered as a functional intestinal disorder. Inflammation in IBS is a quite intriguing theory. The aim of this study was to investigate tumor necrosis factor (TNF)- $\alpha$, interleukin (IL)-1 $\beta$ and IL-6 expression in inflammatory bowel disease (IBD) patients, IBS patients and normal controls. Methods: IBS and IBD patients along with normal controls were recruited in the study. In all groups, 2 pinch biopsies were taken at each of 3 anatomical sites (terminal ileum, cecum, and rectum). IBS patients were also subcategorized according to the syndrome clinical manifestations. Two monoclonal antibodies (mAb), TNF- $\alpha$ mAb and IL-6 mAb, and one polyclonal antibody IL-1 $\beta$ mAb were applied for immunohistochemical analysis. Results: In IBD patients intensity of TNF- $\alpha$ and IL-1 $\beta$ were lower than in IBS patients or controls, while IL-6 was significantly increased comparing to the aforementioned groups. In IBS patients TNF- $\alpha$ was increased comparing to IBD patients or controls, while IL- 6 and IL- $1 \beta$ were similar to controls. In IBS subgroups, TNF- $\alpha$ was lower in diarrhea predominant IBS patients and higher constipation predominant IBS patients. Differences among IBS subgroups regarding IL-6 and IL-1 $\beta$ were nonsignificant. Conclusions: IL-6 seems to be the most important proinflammatory cytokine in IBD patients, while TNF- $\alpha$ could play a more significant role in IBS pathogenesis. (Intest Res 2020;18:115-120)

Key Words: Proinflammatory cytokines; Irritable bowel syndrome; Inflammatory bowel disease

\section{INTRODUCTION}

Irritable bowel syndrome (IBS) is a chronic, fluctuating disorder with frequent relapses that affects approximately $20 \%$ of adults, accounts for $40 \%$ of referrals to gastroenterology clinics, and comprises $12 \%$ of general-practitioner consultations. IBS is a disorder without a clear and uniform biochemical, anatomical or pathophysiological substrate. The most prominent

Received October 1, 2019. Revised November 12, 2019

Accepted December 3, 2019

Correspondence to Vasiliki Galani, Department of Anatomy, Histology,

and Embryology, Medical School University of Ioannina, Dourouti, loannina

45110, Greece. Tel: +30-2651007587, Fax: +30-2651007860

E-mail:vgalani@uoi.gr symptoms are abdominal pain or abdominal discomfort and an altered defecation pattern. As there are, by definition, no biological parameters for diagnostic discretion in IBS, symptoms constitute a reliable basis for classification and diagnosis. Several acknowledged criteria such as "Manning criteria" followed by the "Kruis criteria" and the "Rome criteria (I-III)," have been used in order to establish diagnosis.

IBS has been considered a common functional disorder implying a disorder without a discernible pathophysiological mechanism, thus a nonorganic disorder., ${ }^{2,3}$ Traditionally, IBS has been viewed upon as a disorder where altered GI motility, visceral hypersensitivity, dysregulation of brain-gut axis, altered bowel motility, neurotransmitter imbalances and psychosocial factors are the most important pathophysiological 
factors. ${ }^{4,5}$

The lack of an orchestrator of the IBS mystery is probably the more significant quest regarding the disease. The last few years an emerging theory of inflammation as the key pathophysiological factor in IBS has become quite intruiging. ${ }^{1,6,7}$

The aim of this study was to investigate mucosal levels of TNF- $\alpha$, interleukin (IL)- 6 and IL- $1 \beta$ in inflamed mucosa (IBD patients), in non-inflamed mucosa (normal controls) as well as in assumed non-inflamed mucosa of patients with IBS.

\section{METHODS}

\section{Patients}

IBS and IBD patients along with normal controls were recruited in the study. Characteristics of IBS and IBD patients and normal controls are described at Table 1. Data regarding IBD patients were mostly retrospective, while IBS patients and controls were recruited prospectively. All subjects underwent colonoscopy after cleansing of their whole colon with polyethylene glycol-electrolyte lavage solution. In all cases, 2 pinch biopsies were taken at each of the 3 anatomical sites (terminal ileum, cecum and rectum). IBD was diagnosed upon clinical end endoscopical criteria as well as by biopsy findings. The endoscopic classification for the IBD group was established using Mayo clinic index and UC endoscopic index for severity. ${ }^{8}$ Biopsies obtained from IBD patients with colitis were used as inflammatory disease controls. IBD specimens include patients with CD (CD-terminal ileum), with UC (UC-rectum) and both CD and UC patients (cecum).

IBS patients fulfilled the Rome III criteria and none of them had a clear history of IBD. IBS patients were further subcategorized according to their bowel habits (IBS-D, diarrhea predominant IBS; IBS-C, constipation-predominant IBS; IBS-A, patients with alternating symptoms) in order to detect variations in the expression of TNF- $\alpha$, IL-6, IL-1 $\beta$ in those subgroups. As normal controls were used patients that underwent colonoscopy for polypectomy or investigation of anemia or hema- tochezia or even patients with colon cancer that had a part of their colon surgically removed (bowel parts remote to cancer margins were used). Controls had: (1) macroscopically and histologically normal colonic mucosa; (2) no persistent bowel symptoms; (3) no organic or functional bowel disease; and (4) no history of chronic medical disease. None of IBD, IBS patients or normal control cases received any anti-inflammatory regimen prior to the time of biopsy.

\section{Methods}

Tissue specimens were formalin-fixed, embedded in paraffin cubes and $4-\mu \mathrm{m}$ thick sections were obtained for immunohistochemical study. Immunohistochemical staining was performed on an automated immunostainer (Ventana Benchmark, Strasbourg, France), according to the manufacturer's protocols.

Antibodies directed against TNF- $\alpha$ (dilution 1:100, clone P/ T2; Abcam Inc, Cambridge, UK), IL-6 (dilution 1:100, clone 10C12; Leica Biosystems, Wetzlar, Germany) and IL-1 $\beta$ (Thermo Fisher Scientific Inc, Waltham, MA, USA) were applied. Finally, slides were washed in tap water, dehydrated, and mounted with glass coverslips. Positive controls were used to confirm the adequacy of the staining and negative controls were included and consisted in the same immunohistochemical method with omission of the primary antibody.

For the counting of immunopositive TNF- $\alpha$, IL- 6 and IL-1 $\beta$ cells a semiquantitative score system that considered staining intensity on epithelium and crypts was adopted by using the $\times 40$ objective lens and counting at least 5 nonoverlapping fields selected on the basis they contained immunopositive cells. Intensity of TNF- $\alpha$, IL- 6 and IL- $1 \beta$ staining was evaluated as weak $(+1)$, moderate $(+2)$, intense $(+3)$ or severe $(+4)$ on a subjective basis. All immunohistochemical sections were evaluated by 2 independent experienced pathologists. The grade of inflammation was assessed under the same light microscope at $\times 40$ magnification by the same pathologists.

Statistical analysis was performed with SPSS software. Kruskal-Wallis one-way ANOVA test was used to assess the statisti-

Table 1. Characteristics of IBD Patients, Controls and IBS Subgroups

\begin{tabular}{|c|c|c|c|c|c|c|c|}
\hline \multirow{2}{*}{ Characteristic } & \multicolumn{3}{|c|}{ IBS } & \multicolumn{3}{|c|}{ IBD } & \multirow{2}{*}{ Controls } \\
\hline & IBS-D & IBS-C & IBS-A & Terminal ileum & Cecum & Rectum & \\
\hline Mean age (yr) & 44 & 54 & 43 & 35 & 38 & 46 & 46 \\
\hline Range (yr) & $19-61$ & $23-66$ & $40-52$ & $17-61$ & $24-48$ & $21-60$ & $18-72$ \\
\hline Number & 5 & 9 & 3 & 18 & 18 & 14 & 19 \\
\hline
\end{tabular}

IBS subtypes: IBS-D, predominant symptom diarrhea; IBS-C, predominant symptom constipation; IBS-A, patients with alternating symptoms. 
cal differences between the aforementioned groups. $P<0.05$ indicated a statistically significant difference.

\section{Ethical Considerations}

This study was conducted according to the Ethical Guidelines for Medical and Health Research Involving Human Subjects. The present study was approved by the Ethics Review Committee of University of Ioannina (approval No. 515 /11-11-
2003). No additional permissions were required to review the patient records, including the hospitals from which the records were obtained.

\section{RESULTS}

\section{TNF- $\alpha$}

Intensity of TNF- $\alpha$ was lower in IBD patients through terminal

Table 2. TNF- $\alpha$, IL-6 and IL-1 $\beta$ in Terminal Ileum, Cecum and Rectum of IBS patients, IBD Patients and Controls

\begin{tabular}{|c|c|c|c|c|c|c|}
\hline \multirow[b]{2}{*}{ Bowel parts, cytokines } & \multicolumn{2}{|c|}{ IBD } & \multicolumn{2}{|c|}{ IBS } & \multicolumn{2}{|c|}{ Controls } \\
\hline & $\begin{array}{l}\text { Epithelium } \\
\text { intensity }\end{array}$ & $\begin{array}{l}\text { Crypts } \\
\text { intensity }\end{array}$ & $\begin{array}{l}\text { Epithelium } \\
\text { intensity }\end{array}$ & $\begin{array}{c}\text { Crypts } \\
\text { intensity }\end{array}$ & $\begin{array}{l}\text { Epithelium } \\
\text { intensity }\end{array}$ & $\begin{array}{l}\text { Crypts } \\
\text { intensity }\end{array}$ \\
\hline \multicolumn{7}{|l|}{ Terminal ileum } \\
\hline TNF- $\alpha$ & $1.00^{\mathrm{a}}$ & 0.68 & $2.38^{\mathrm{b}}$ & 2.00 & $1.94^{b}$ & 1.61 \\
\hline IL-6 & $2.17^{\mathrm{a}}$ & $1.89^{\mathrm{a}}$ & $1.65^{b}$ & $1.22^{b}$ & $1.95^{\mathrm{b}}$ & $1.70^{\mathrm{b}}$ \\
\hline $\mathrm{IL}-1 \beta$ & $2.31^{\mathrm{a}}$ & $2.31^{\mathrm{a}}$ & $2.70^{a, b}$ & $2.95^{a, b}$ & $2.84^{\mathrm{b}}$ & $2.85^{\mathrm{b}}$ \\
\hline \multicolumn{7}{|l|}{ Cecum } \\
\hline TNF- $\alpha$ & $0.80^{\mathrm{a}}$ & 0.80 & $2.90^{b}$ & 2.35 & $2.38^{c}$ & 2.00 \\
\hline IL-6 & $2.31^{\mathrm{a}}$ & $2.16^{a}$ & $1.72^{b}$ & $1.41^{\mathrm{b}}$ & $1.76^{b}$ & $1.40^{\mathrm{b}}$ \\
\hline IL-1 $\beta$ & $2.65^{\mathrm{a}}$ & $2.56^{\mathrm{a}}$ & $3.05^{b}$ & $3.10^{b}$ & $3.25^{b}$ & $2.65^{b}$ \\
\hline \multicolumn{7}{|l|}{ Rectum } \\
\hline TNF- $\alpha$ & $1.17^{\mathrm{a}}$ & 1.17 & $2.55^{b}$ & 2.30 & $2.63^{b}$ & $2.15^{b}$ \\
\hline IL-6 & $1.87^{\mathrm{a}}$ & $2.08^{\mathrm{a}}$ & $1.73^{b}$ & $1.46^{\mathrm{b}}$ & $1.55^{b}$ & $1.47^{b}$ \\
\hline IL-1 $\beta$ & $2.54^{a}$ & $2.46^{\mathrm{a}}$ & $2.91^{b}$ & $2.95^{\mathrm{b}}$ & $3.10^{\mathrm{b}}$ & $2.89^{b}$ \\
\hline
\end{tabular}

Statistically significant; ${ }^{a} P<0.05 .,{ }^{b} P<0.01$, and ${ }^{c} P<0.001$.

IL, interleukin.

Table 3. TNF- $\alpha$, IL-6, IL-1 $\beta$ in Terminal Ileum, Cecum, and Rectum of IBS Subgroups

\begin{tabular}{|c|c|c|c|c|c|c|}
\hline \multirow[b]{2}{*}{ IBS subtypes } & \multicolumn{2}{|c|}{ Terminal ileum } & \multicolumn{2}{|c|}{ Cecum } & \multicolumn{2}{|c|}{ Rectum } \\
\hline & $\begin{array}{l}\text { Epithelium } \\
\text { intensity }\end{array}$ & $\begin{array}{c}\text { Crypts } \\
\text { intensity }\end{array}$ & $\begin{array}{l}\text { Epithelium } \\
\text { intensity }\end{array}$ & $\begin{array}{l}\text { Crypts } \\
\text { intensity }\end{array}$ & $\begin{array}{l}\text { Epithelium } \\
\text { intensity }\end{array}$ & $\begin{array}{c}\text { Crypts } \\
\text { intensity }\end{array}$ \\
\hline \multicolumn{7}{|l|}{ TNF- $\alpha$} \\
\hline IBS-D & $2.00^{\mathrm{a}}$ & $2.00^{\mathrm{a}}$ & $2.67^{\mathrm{a}}$ & $2.00^{\mathrm{a}}$ & $2.60^{\mathrm{a}}$ & $2.20^{\mathrm{a}}$ \\
\hline IBS-C & $2.33^{\mathrm{a}}$ & 1.77 & 3.22 & 2.77 & 2.55 & 2.44 \\
\hline IBS-A & $2.33^{\mathrm{a}}$ & 2.67 & 3.00 & 3.00 & 3.00 & 2.67 \\
\hline \multicolumn{7}{|l|}{ IL-6 } \\
\hline IBS-D & $1.60^{\mathrm{a}}$ & $1.00^{2}$ & $1.50^{\mathrm{a}}$ & $1.50^{a}$ & $3.20^{\mathrm{a}}$ & $2.00^{b}$ \\
\hline IBS-C & $1.55^{\mathrm{a}}$ & $1.14^{\mathrm{a}}$ & $1.44^{2}$ & $1.00^{\mathrm{a}}$ & $2.90^{\mathrm{a}}$ & $1.00^{\mathrm{a}}$ \\
\hline IBS-A & $1.77^{\mathrm{a}}$ & $1.50^{\mathrm{a}}$ & $1.67^{\mathrm{a}}$ & $1.33^{\mathrm{a}}$ & $3.00^{\mathrm{a}}$ & $1.00^{\mathrm{a}}$ \\
\hline \multicolumn{7}{|l|}{ IL-1 $1 \beta$} \\
\hline IBS-D & $3.00^{\mathrm{a}}$ & $2.60^{2}$ & $2.75^{a}$ & $3.00^{\mathrm{a}}$ & $3.20^{\mathrm{a}}$ & $3.00^{\mathrm{a}}$ \\
\hline IBS-C & $2.89^{\mathrm{a}}$ & $3.10^{\mathrm{a}}$ & $3.00^{a}$ & $3.00^{\mathrm{a}}$ & $2.90^{\mathrm{a}}$ & $3.10^{\mathrm{a}}$ \\
\hline IBS-A & $2.67^{\mathrm{a}}$ & $3.30^{a}$ & $3.00^{\mathrm{a}}$ & $3.00^{a}$ & $3.00^{\mathrm{a}}$ & $3.00^{\mathrm{a}}$ \\
\hline
\end{tabular}

Statistically significant; ${ }^{a} P<0.05 .,{ }^{b} P<0.001$.

IL, interleukin; IBS subtypes: IBS-D, predominant symptom diarrhea; IBS-C, predominant symptom constipation; IBS-A, patients with alternating symptoms. 
ileum, cecum and rectum, compared to IBS patients and controls $(P<0.05)$ (Table 2). A nonsignificant increase of TNF- $\alpha$ intensity in IBS patients compared to controls was showed, except at cecum epithelium $(P=0.03)$.

\section{IL-6}

Intensity of IL-6 appeared higher in IBD patients compared to IBS patients and controls (IBD vs. IBS, $P<0.05$ ) throughout the bowel (Table 2). When comparing expression of IL-6 in IBS patients and controls, no definite pattern was revealed.

\section{IL-1 $\beta$}

Intensity of IL-1 $\beta$ was lower in IBD patients compared to IBS patients and controls (IBD vs. controls, $P<0.05$; IBD vs. IBS, $P<0,05$ at cecum, rectum) (Table 2 ). Intensity of IL- $1 \beta$ was rather similar in IBS patients and controls.

\section{IBS Subgroups}

Intensity of TNF- $\alpha$ was lower in IBS-D patients throughout the epithelium and crypts of terminal ileum, cecum and rectum in comparison with IBS-C or IBS-A patients (Table 3). Intensity of TNF- $\alpha$ in IBS-A patients was higher at the rectum and terminal ileum crypts as well as at rectum epithelium $(P>0.05)$. No statistically significant differences were found in intensity of IL-6 at terminal ileum, cecum and rectum of IBS subgroups, except a significant raise in rectum crypts of IBS-D patients (IBS-D vs. IBS-C/IBS-A, $P=0.001$ ) (Table 3). Finally, intensity of IL-1 $\beta$ was rather similar in all IBS subgroups without significant differences at the terminal ileum, cecum and rectum.

\section{DISCUSSION}

Investigation of pathogenesis in IBDs by analyzing the inflamed mucosa from patients with UC and CD has revealed the increased expression of certain proinflammatory cytokines such as IL-1, IL-6, IL-8, and TNF- $\alpha .{ }^{9}$ IL-6 is a pleiotropic cytokine that exerts certain proinflammatory effects and is associated with neoplasia and autoimmune disorders. ${ }^{10}$ Stimulation of IL-6 results in a maximal induction of nuclear factor kB (NF-kB) activation and NF-kB nuclear translocation and induces expression of intercellular adhesion molecule 1, an adhesion molecule shown to be important in the neutrophil-epithelial interactions in IBD. ${ }^{11}$ IL-6 plays a central role in several immunologic responses during the development of IBD, and circulating levels of IL-6 are associated with many clinical features of CD and UC. ${ }^{12}$
IL-6 is expressed in a significantly higher amount in both serum and tissue of patients with active IBD and its levels have been correlated with the severity of the disease and are associated with the prediction of disease activity. T-cell accumulation, mediated by apoptosis resistance, eventually leads to chronic inflammation and can be inhibited by anti-IL-6 receptor antibodies. ${ }^{13,14}$ Overall, several studies have highlighted the role of IL-6 in innate and adaptive immune responses and suggest that deregulation of these pathways can contribute to the progression of chronic disease. ${ }^{15}$

TNF- $\alpha$ and IL- $1 \beta$ play important roles in the regulation of the immunity, the inflammatory response and the cell growth and death of normal and cancerous cells. ${ }^{16-18}$ IL-1 seems to be substantive in the pathogenesis of IBD because of its immunological up-regulatory and proinflammatory activities. IL-1, primarily secreted by monocytes and macrophages, activates intestinal macrophages, neutrophils, fibroblasts, and smoothmuscle cells, inducing them to secrete prostaglandins, proteases, and other soluble mediators of inflammation, and chemotactic cytokines. ${ }^{19}$

TNF- $\alpha$ expression in human macrophages was discovered in the colonic tissue and macrophages in both patients with $\mathrm{CD}$ and UC and serum levels of TNF- $\alpha$ correlate with clinical and laboratory indices of intestinal disease activity. ${ }^{12}$ TNF- $\alpha$ is considered to play an essential role in the pathogenesis of mucosal inflammation in IBD as supported by human and animal studies: (1) in a clinical trial approximately two-thirds of CD patients responded to treatment with a single infusion of anti-TNF- $\alpha$ chimeric monoclonal antibody; (2) amelioration of inflammation following anti-TNF- $\alpha$ treatment in several animal models of intestinal inflammation is presented; (3) the development of a "Crohn's-like" phenotype in mice that overexpress TNF- $\alpha$ has been shown. ${ }^{9}$ TNF- $\alpha$ antibodies have a documented initial effect in $60 \%$ to $70 \%$ of patients with moderate to severe luminal and/or fistulizing IBD and approximately $30 \%$ of patients achieve remission after a relatively short treatment period.$^{20}$ Nevertheless, the effect seems to decrease during long-term treatment.

In our study intensity of TNF- $\alpha$ was shown decreased in IBD patients in comparison with IBS patients or controls. Several studies have demonstrated increased mucosal levels of TNF- $\alpha$ in IBD patients, ${ }^{21,22}$ whereas others were unable to detect increased levels of TNF- $\alpha .{ }^{23,24}$ Likewise, the mucosal levels of IL$1 \beta$ were decreased in IBD patients comparing to IBS patients or controls. On the contrary IL-6 mucosal levels were augmented in IBD patients comparing to the aforementioned groups, 
which corresponds with several studies that place IL-6 as a key factor in IBD. ${ }^{11,25}$

Furthermore, it is beguiling that TNF- $\alpha$ mucosal levels were increased in IBS patients in comparison to IBD patients or controls, showing that TNF- $\alpha$ could participate in IBS pathogenesis. Probably, additional research of TNF- $\alpha$ serum levels in IBs patients would provide further data, considering the confirmed elevation in IBD patients, demonstrated in several studies. ${ }^{12}$ Levels of IL-6 and IL-1 $\beta$ were similar with those detected in controls revealing possibly a nonsignificant role in IBS. Analyzing IBS subgroups based on symptomatology revealed subtle differences only regarding TNF- $\alpha$, showing a decrease in IBS-D patients and an increase in IBS-C patients, and no differences in IL- 6 and IL-1 $\beta$ in IBS subgroups.

Unprotected elevated levels of TNF- $\alpha$, IL- 6 and IL- $1 \beta$ in controls could be attributable to normal intestinal inflammation. ${ }^{26}$ Normal bowel inflammation is a normal response that prevents bowel injury by its ability to fit perfectly into multiple proinflammatory challenges and is therefore essential to homeostasis. The intestine develops and functions within a complex and large microbial load and a steady stream of dietary antigens leading to a "normal inflammation" condition. Anti-inflammatory cytokines such as IL-10 could contribute to diminishing inflammatory procedures in normal controls.

In conclusion, our study demonstrated that IL-6 is probably the most important proinflammatory cytokine in IBD patients, whereas in IBS patients, TNF- $\alpha$ seems a more challenging factor in the disease pathogenesis. Further studies investigating anti-inflammatory or other proinflammatory cytokines in IBS, would provide additional information in the ambiguous pathophysiology mechanisms of IBS as well as the IL-17/Th17 (Thelper 17) axis which is assumed to play an important role in regulating intestinal tissue inflammation, ${ }^{27}$ and thus, contribute to more effective management.

\section{FINANCIAL SUPPORT}

The authors received no financial support for the research, authorship, and/or publication of this article.

\section{CONFLICT OF INTEREST}

No potential conflict of interest relevant to this article was reported.

\section{AUTHOR CONTRIBUTION}

Conceptualization: Grammeniatis V. Methodology: Mitselou A, Grammeniatis V, Galani V. Formal analysis: Katsanos K. Project administration: all authors. Writing - original draft: Grammeniatis V, Varouktsi A, Papadatos SS. Writing - review \& editing: Mitselou A, Galani V. Approval of final manuscript: all authors.

\section{ORCID}

Mitselou A https://orcid.org/0000-0001-7434-260X

Grammeniatis V https://orcid.org/0000-0002-3315-6031

Papadatos SS

Katsanos K

Galani V

https://orcid.org/0000-0001-9536-5464 https://orcid.org/0000-0002-3273-0417 https://orcid.org/0000-0002-6130-0061

\section{REFERENCES}

1. Chadwick VS, Chen W, Shu D, et al. Activation of the mucosal immune system in irritable bowel syndrome. Gastroenterology 2002;122:1778-1783.

2. Oberndorff-Klein Woolthuis AH, Brummer RJ, de Wit NJ, Muris JW, Stockbrügger RW. Irritable bowel syndrome in general practice: an overview. Scand J Gastroenterol Suppl 2004;(241): $17-22$.

3. Drossman DA, Camilleri M, Mayer EA, Whitehead WE. AGA technical review on irritable bowel syndrome. Gastroenterology 2002;123:2108-2131.

4. Cayley WE Jr. Irritable bowel syndrome. BMJ 2005;330:632.

5. Spiller RC. Irritable bowel syndrome. Br Med Bull 2005;72:1529.

6. Ohman L, Simrén M. Pathogenesis of IBS: role of inflammation, immunity and neuroimmune interactions. Nat Rev Gastroenterol Hepatol 2010;7:163-173.

7. Akiho H, Ihara E, Nakamura K. Low-grade inflammation plays a pivotal role in gastrointestinal dysfunction in irritable bowel syndrome. World J Gastrointest Pathophysiol 2010;1:97-105.

8. Travis SP, Schnell D, Krzeski P, et al. Developing an instrument to assess the endoscopic severity of ulcerative colitis: the Ulcerative Colitis Endoscopic Index of Severity (UCEIS). Gut 2012;61:535-542.

9. Papadakis KA, Targan SR. Role of cytokines in the pathogenesis of inflammatory bowel disease. Annu Rev Med 2000;51: 289-298

10. Galani V, Constantopoulos S, Manda-Stachouli C, et al. Addi- 
tional proteins in BAL fluid of Metsovites environmentally exposed to asbestos: more evidence of "protection" against neoplasia? Chest 2002;121:273-278.

11. Wang L, Walia B, Evans J, Gewirtz AT, Merlin D, Sitaraman SV. IL-6 induces NF-kappa B activation in the intestinal epithelia. J Immunol 2003;171:3194-3201.

12. Sanchez-Munoz F, Dominguez-Lopez A, Yamamoto-Furusho JK. Role of cytokines in inflammatory bowel disease. World J Gastroenterol 2008;14:4280-4288.

13. Mudter J, Neurath MF. Apoptosis of T cells and the control of inflammatory bowel disease: therapeutic implications. Gut 2007;56:293-303.

14. Kallen KJ. The role of transsignalling via the agonistic soluble IL-6 receptor in human diseases. Biochim Biophys Acta 2002; 1592:323-343.

15. Rose-John S, Scheller J, Elson G, Jones SA. Interleukin-6 biology is coordinated by membrane-bound and soluble receptors: role in inflammation and cancer. J Leukoc Biol 2006;80:227236.

16. Kastamoulas M, Chondrogiannis G, Kanavaros P, et al. Cytokine effects on cell survival and death of A549 lung carcinoma cells. Cytokine 2013;61:816-825.

17. Chondrogiannis G, Kastamoulas M, Kanavaros P, et al. Cytokine effects on cell viability and death of prostate carcinoma cells. Biomed Res Int 2014;2014:536049.

18. Galani V, Kastamoulas M, Varouktsi A, Lampri E, Mitselou A, Arvanitis DL. IFNs-signaling effects on lung cancer: an up-todate pathways-specific review. Clin Exp Med 2017;17:281-289.

19. Scaldaferri F, Correale C, Gasbarrini A, Danese S. Mucosal biomarkers in inflammatory bowel disease: key pathogenic players or disease predictors? World J Gastroenterol 2010;16: 2616-2625.

20. Martinsen TC, Herter R, Dybdahl JH, Waldum HL. Use of TNFalpha antibodies in treatment of inflammatory bowel disease. Tidsskr Nor Laegeforen 2010;130:273-277.

21. Maeda M, Watanabe N, Neda H, et al. Serum tumor necrosis factor activity in inflammatory bowel disease. Immunopharmacol Immunotoxicol 1992;14:451-461.

22. Andus T, Targan SR, Deem R, Toyoda H. Measurement of tumor necrosis factor alpha mRNA in small numbers of cells by quantitative polymerase chain reaction. Reg Immunol 1993; 5:11-17.

23. Youngman KR, Simon PL, West GA, et al. Localization of intestinal interleukin 1 activity and protein and gene expression to lamina propria cells. Gastroenterology 1993;104:749-758.

24. Oliva-Hemker M, Fiocchi C. Etiopathogenesis of inflammatory bowel disease: the importance of the pediatric perspective. Inflamm Bowel Dis 2002;8:112-128.

25. Ruffolo C, Scarpa M, Faggian D, et al. Cytokine network in rectal mucosa in perianal Crohn's disease: relations with inflammatory parameters and need for surgery. Inflamm Bowel Dis 2008;14:1406-1412.

26. Fiocchi C. What is "physiological" intestinal inflammation and how does it differ from "pathological" inflammation? Inflamm Bowel Dis 2008;14 Suppl 2:S77-S78.

27. Monteleone I, Pallone F, Monteleone G. Interleukin-23 and Th17 cells in the control of gut inflammation. Mediators Inflamm 2009;2009:297645. 